This item was submitted to Loughborough's Research Repository by the author.

Items in Figshare are protected by copyright, with all rights reserved, unless otherwise indicated.

\title{
Sustainability: methods and practices
}

PLEASE CITE THE PUBLISHED VERSION

http://www.bloomsbury.com/uk/the-handbook-of-design-for-sustainability-9780857858528/

\section{PUBLISHER}

(c) Bloomsbury Publishing PIc

\section{VERSION}

AM (Accepted Manuscript)

\section{PUBLISHER STATEMENT}

This work is made available according to the conditions of the Creative Commons Attribution-NonCommercialNoDerivatives 4.0 International (CC BY-NC-ND 4.0) licence. Full details of this licence are available at: https://creativecommons.org/licenses/by-nc-nd/4.0/

\section{LICENCE}

CC BY-NC-ND 4.0

\section{REPOSITORY RECORD}

Bhamra, T.A., Ricardo J. Hernandez-Pardo, and Richard G. Mawle. 2019. "Sustainability: Methods and Practices". figshare. https://hdl.handle.net/2134/18658. 


\title{
SUSTAINABILITY - METHODS AND PRACTICES
}

Tracy Bhamra, Ricardo Hernandez and Richard Mawle

Loughborough Design School

Loughborough University

Loughborough, LE11 3TU, UK

t.bhamra@lboro.ac.uk

\begin{abstract}
This chapter provides an overview of the methods and practices being used to address design for sustainability. Different approaches to aid design for sustainability are introduced ranging from those which focus purely on incremental design such as improving existing products, or redesign, through to those which result in more radical innovations such as developing new concepts or moving towards system innovation. The chapter outlines these approaches in detail and discuss their strengths and weaknesses. A number of case studies are used to illustrate the way in which these different approaches have been applied in practice and the resulting products, services or systems. Finally conclusions are drawn around the benefits of applying these approaches, the limitations are discussed and the future directions needed for the field are explored in order to illustrate how current research in this area can be developed further for use by designers.
\end{abstract}

\section{KEYWORDS}

Design Methods, Incremental Innovation, Radical Innovation 


\section{BIOGRAPHICAL NOTE}

Professor Tracy Bhamra is Professor of Sustainable Design and Dean of Loughborough Design School, Loughborough University, UK. Her research lies in the area of design for sustainability, its application and effectiveness. This research has involved collaboration with multi-national as well as small and medium sized companies from the automotive, electrical and electronic, textile and clothing and energy generation industry sectors. Her book Design for Sustainability: A Practical Approach was published by Gower in 2007.

\section{INTRODUCTION TO DESIGN FOR SUSTAINABILITY APPROACHES}

Design for sustainability is design with the intention to achieve sustainable outputs. It is design that considers the environmental and social impacts of a product, service or system at the same level that economic concerns are considered (Bhamra \& Lofthouse, 2007). When implementing this within design projects it must take a holistic perspective taking into account all the life-cycle stages of the product, service or system from extraction of raw materials, manufacturing, distribution and use to end-of-life scenarios to influence the outputs of the design process.

This systemic idea of design has made the public and private agendas on sustainability turn their attention towards design for sustainability as an engine of positive transformation. On one side improving environmental performance of products, services and systems increasing energy efficiency, encouraging the use of recycled materials or reducing the use of toxic substances. On the other achieving social benefits associated with issues such as usability, fair sourcing, design for human needs and socially responsible use of products and services. However design for sustainability has also a great potential to change attitudes and behaviours. Within the radical dimension of innovation, design for sustainability can help 
to define a new direction, new lifestyles and new ways to identify and satisfy people's needs in environmentally efficient, socially equitable and profitable ways.

Design for sustainability can respond to the necessity to find a new direction for the way in which products and services are produced and consumed around the world. Designers should take this new direction to lead their projects and influence, through design, other dimensions in organizations, in communities, in private and public bodies. These changes and influences can be achieved by different routes. Design for sustainability can be described as a journey, broken down into different stages moving from incremental design to radical innovations (Brezet, 1997).

In organizational terms there is a need for structural changes rather than simply using new technologies to achieve more sustainable business. New scenarios of business with greater economic, social and environmental value are being explored rather than just reducing resource use (Rainey, 2006). Design has a major role in this organizational transformation towards sustainable businesses. It has been established for example that almost eighty per cent of the costs of product development, manufacture and use are determined in the design stage (Mascle \& Zhao, 2008). So, the earlier environmental and social factors are considered in the design process, the greater the possible savings and positive performance of the product. This inclusion of environmental and social factors can be done through incremental innovations such as design for easy disassembly or packaging reduction, but it can also be executed in more radical ways such as designing new business concepts such as product service systems (PSS). This idea of the different routes to embark on design for sustainability is presented in Figure 1. This representation implies that the journey can start at any stage and that the more radical the approach the greater number of less radical changes can also be included. For example, system innovation includes concepts, tools and principles from improvement, redesign and new concepts, but considered from a different point of view. 


\section{System innovation}

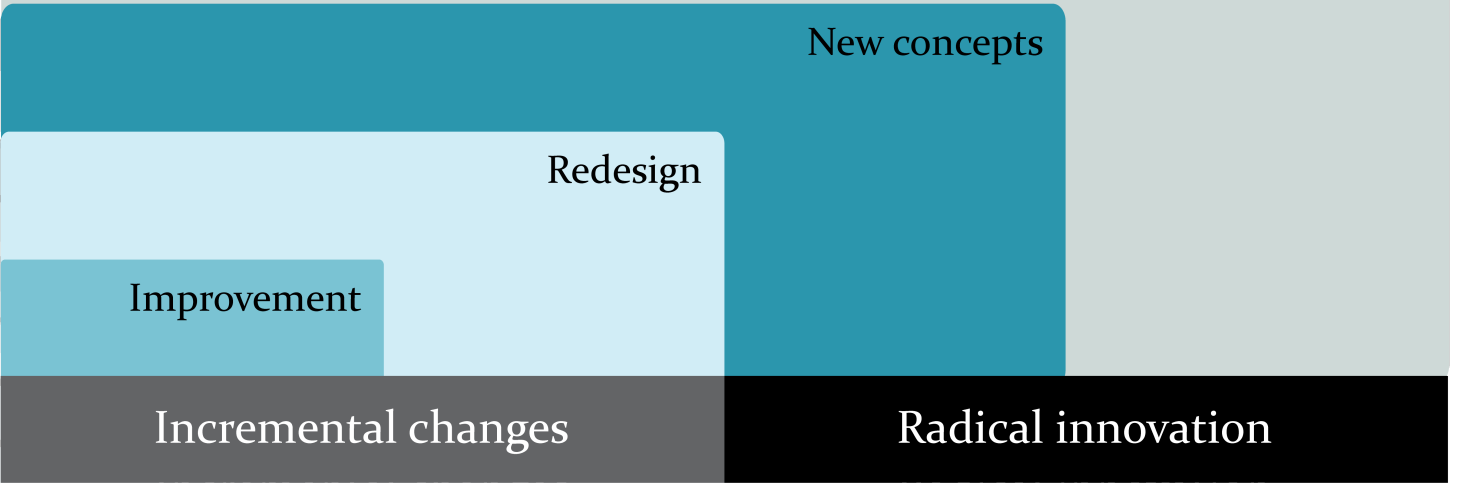

Figure 1: Different approaches to embark design for sustainability

\section{Approaches}

The different approaches that can be used to embark on design for sustainability, outlined in Figure 1, are explored in this section. Their use is explained and examples of implementation given.

\section{Improvement}

Improvement is an incremental approach that can be used in design for sustainability. It is at the base of the possible routes that a designer can take to pursue sustainable products, services and systems. The idea is to make small modifications to the outputs of design by considering, as far as possible, both environmental and social aspects that result in products, services and systems that have better performance in the three dimensions: people, planet and profit. Usually these modifications are related to current legislation and to continual benchmarking within the industry sector, influenced by regulations and policies, both of which are drivers for change. 
Designers can take advantage of the standards developed to enable their designs to consider best practice, for example, in the use of certain materials, packaging and recyclability levels. These standards for example include BS EN 13427:2004, which concerns the use of packaging and packaging waste in the UK to comply with the European Packaging and Packaging Waste Directive (94/62/EC) (European Parliament Council, 1994). This standard is complemented by BS EN 13430:2004, which is focused on the recyclability of packaging materials; BS EN 13431:2004, which deals with energy recovery of used packaging; BS EN 13432:2000, which relates to packaging recoverable through composting and biodegradation, and BS EN 13429:2004, which is oriented to packaging reuse. These types of standards give a framework that when combined with design for sustainability can help designers not only to comply with legislation but also produce innovative designs with greater environmental and social value.

In the case of electrical and electronic products one of the main pieces of legislation introduced in Europe is the Directive 2002/96/EC on WEEE (Waste Electrical and Electronic Equipment) that requires producers to take responsibility for their products at the end of their life. This directive affects all producers of electric and electronic products who want to commercialize their products in Europe (Bhamra \& Lofthouse, 2007). The final objective of this directive is to reduce the amount of e-waste by encouraging producers to take actions that lead to the reuse, recycling and recovery of their products. Designers have to be conscious of these regulatory frameworks in order to comply with the law, but also because it can create an opportunity to modify designs and put products and services in a better strategic position.

In terms of energy consumption the Ecodesign Directive (2009/125/EC) finalized in 2009 defines a framework for producers of energy using products to improve the energy efficiency of their products (European Parliament Council, 2009). More specific standards, frameworks and directives related to environmental management can be found in other 
industries that affect the design of products and services, such as automotive, chemicals and printing. This complexity of legislation and standards makes improvement a challenging approach, even if it is implemented by the inclusion of small changes in the design process. Making design for sustainability part of the environmental management system (EMS) inside the organization could be one way to ensure that criteria such as energy efficiency, recyclability, waste and replacement of banned substances are taken into account from the outset of the product, service or system development. An EMS focussing on incremental improvements through constant evaluation of the system can be useful to ensure that these can be related to sustainable product, service or system design.

Finally following this approach of incremental changes through improvement, designers should aim to gain an understanding of what design for sustainability means and reflect this through concrete actions in the design process. Some of these actions can be related, for example, to selecting low impact materials by taking into account recycling rates, avoiding toxic substances according to the legislation or replacing non-renewable materials. In terms of energy efficiency, this can be achieved by identifying whereabouts in the lifecycle the product, service or system consumes energy and encouraging low consumption. This can be done by active or passive means, for example, displaying information to the user or embedding mechanisms to turn off the product, service or system when not in use (Brezet \& Van Hemel, 1997). Finally, considering waste and what the possible options are to dispose of the product or components of the system at the end of their life. The available options are shown as a waste hierarchy in Figure 2 (European Parliament Council, 2008). 


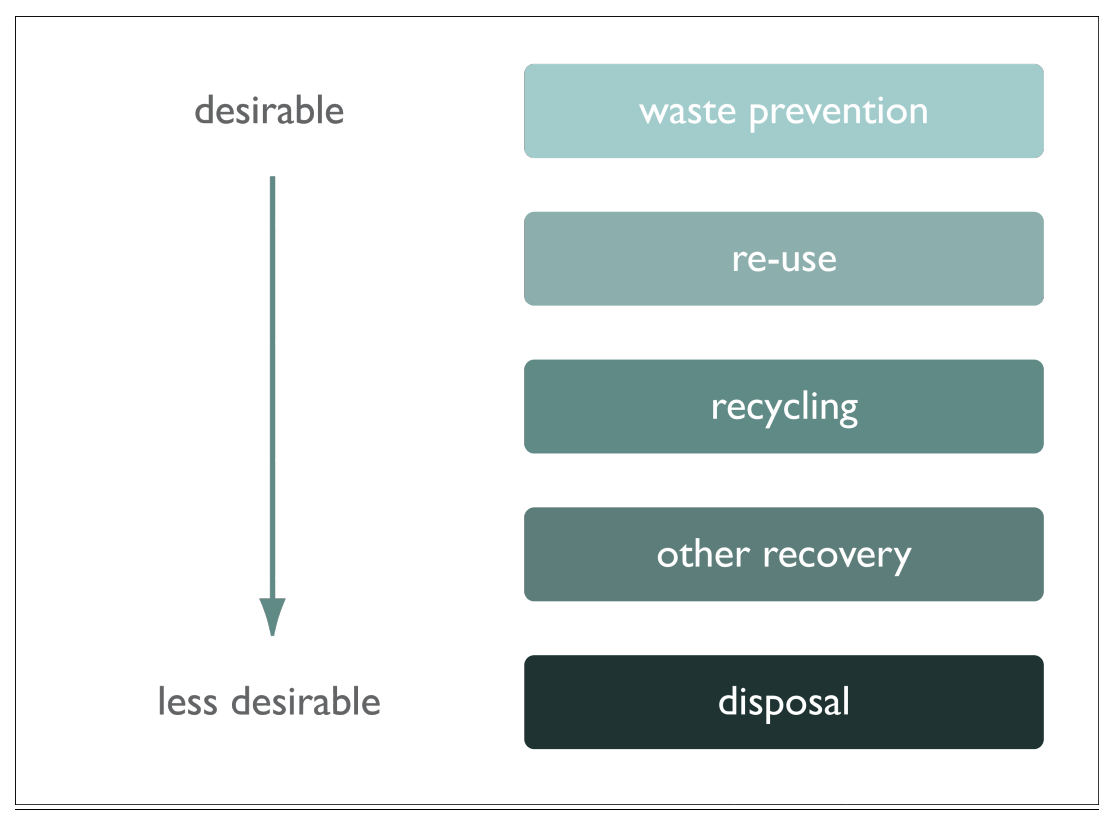

Figure 2: Waste Hierarchy

Washing Machines, Panasonic Case: In general the design of washing machines in terms of functionality and expected results is very similar to twenty years ago. However the consumption of energy during use, that represents an important environmental impact, has been reduced considerably by a process of continual improvement in the design process to reach the targets established by law. Panasonic, for example, has been achieving environmental impact reduction in their washing machines by the incorporation of low washing temperature cycles, auto power off functions, short washing cycles and more recently inverter control technologies (Panasonic, 2011).

In this example it is possible to see a continual improvement approach whereby small modifications in the design of the final product are not only innovative but also improve sustainability performance. These modifications in the product design have not come all at once but are the result of years of development. However, even small modifications in design can have large implications in the interaction between customers and products. Low temperature cycles and short washing cycles, for example, could mean important changes in 
behaviour of consumers. It is a risk for a company to embark on an improvement approach, and for that reason it is also important to support the changes with mechanisms that consumers can understand and value. Panasonic certify their washing machines with widely known eco-labels and with their own labels such as Energy Saving, Good Housekeeping Institute, Aquaprotection System, and Ecoideas to fulfil this purpose, communicate its strategy and create value around environmental and social improvements (Panasonic, 2011).

\section{Redesign}

Though still an incremental change, redesign is a more proactive approach than 'Improvement' and considers the impact of a design over its whole life-cycle. Whilst an overall design concept would remain unchanged, modifying the way in which design details are executed can lead to reductions in resource use, such as the decreasing the amount of materials used and how much energy consumed throughout its life.

In order to successfully redesign a product, service or system it is important to have a clear understanding of the resources required in the creation of the current design. The initial step in this process is to examine the whole life-cycle of the existing entity so that it can be assessed. As shown in Figure 3, the life-cycle has several stages, starting with the extraction and processing of raw materials, followed by their conversion into components. These parts are then assembled, packaged, and distributed. Once purchased by the consumer there is a use phase, which ultimately leads to disposal, followed by any reuse or recycling that may occur. All stages in the life-cycle of a product, service or system consume natural resources, either directly as materials or indirectly as energy, and in turn create an environmental impact in the form of emissions or waste (Fiksel, 2009). 


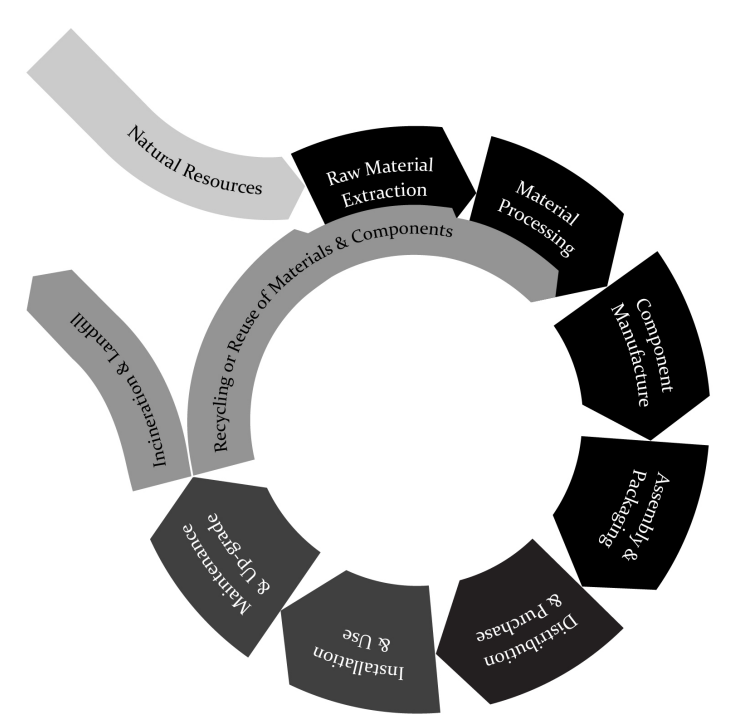

Figure 3: Product Life-cycle Phases

To make an informed judgement on the best way to minimize any ecological impact, a proper evaluation of the full effect of the life-cycle must be made, and this is generally done using a Life-cycle Assessment (LCA) technique. There are numerous LCA tools available, ranging in complexity, but in essence they all aim to quantify the inputs and outputs of the item being evaluated by breaking down the life-cycle into manageable steps and calculating its environmental impact (ISO, 2006). A variety of different metrics can be used to achieve this, but embodied energy, carbon footprint and water usage are some of the most common. Having made this assessment it is then possible to identify the appropriate areas for redesign, and it also enables improvements to be quantified and compared to the original.

Once an assessment of the existing product, service or system has been made the points in the life-cycle that have greatest impact can be identified, and the most appropriate redesign strategies can be more easily identified. The following table shows redesign strategies as defined by Van Hemel (1998). 
Table 1: Design for Environment Strategies (Van Hemel, 1998)

Strategy 1: Select low-impact materials
- Choose clean materials
- Choose renewable materials
- Choose materials with a low energy content
- Choose recycled materials

Strategy 2: Reduction of material usage

- Reduction of weight

- Reduction of (transport) volume

Strategy 3: Optimization of production techniques

- Choose alternative production techniques

- Fewer production steps

- Low/clean energy consumption

- Less production waste

- Few/clean production consumables

Strategy 4: Optimizing the distribution system

- Little/clean/reusable packaging

- Energy-efficient means of transport

- Energy-efficient logistics

\section{Strategy 5: Reduction of the user impact}

- Ensure low energy consumption

- Choose a clean energy source

- Reduce the amount of consumables required

- Choose clean consumables

- No waste of energy or consumables

\section{Strategy 6: Optimization of initial lifetime}

- Increase reliability and durability

- Ensure easy maintenance and repairs

- Ensure a modular, adaptable product structure

- Aim to achieve a classic design

- Ensure a strong product-user relation

Strategy 7: Optimization of the end-of-life system

- Stimulate reuse of the entire product

- Stimulate remanufacturing and refurbishing

- Stimulate material recycling

- Stimulate safe incineration with energy recovery

- Ensure the safe disposal of product scrap

When considering the production and supply of materials or components Strategies 1 and 2 are important because they focus on selecting materials with a low environmental impact as well as reducing the volume and number of materials. For the manufacture and 
assembly of components Strategy 3 encourages the selection of clean production techniques, minimizing the energy used, and reducing the amount of material waste. The issues that arise in the distribution phase are covered by Strategy 2 and 4; the size and weight of packaging can have an important impact on type of transport that can be used and how efficiently it can be organized. It is also important to take account of packaging and whether it can be reused or recycled. During the use phase it is often the energy required in operation that has the biggest impact, though as Strategy 5 highlights consumables may also be an issue worth examining. There are also situations where the energy invested prior to use is the most significant factor, in this case Strategy 6 should be paramount, it is concerned with maximizing longevity through initial reliability and ease of upgrade or repair. Finally, Strategy 7 is concerned with end-of-life and how this can be best optimized to minimize waste. Here there is a hierarchy (See Figure 2), with reuse being the preferred route, though if this is not feasible recycling should be made as easy as possible and any remaining material should be disposed of safely.

The process of taking an existing design, looking at its life-cycle, assessing where it has the largest repercussions, then applying a set of strategies to reduce these can help minimize its environmental impact. By taking this type of systematic approach to the redesign of products, services or systems it is also possible to reduce costs, because the efficient use of resources is both ecologically and commercially beneficial. However, there is a limit on what can be achieved without a more radical change and the creation of new design concepts.

Herman Miller, Mirra Chair: In essence the design of office chairs has not altered greatly for many years, but Herman Miller have earned a reputation for creating iconic seating with enduring desirability. In addition, they have managed to combine this aesthetic allure with enhanced ergonomics and improvements in environmental performance. 
Herman Miller used the sustainable McDonough Braungart Design Chemistry (MBDC) Cradle to Cradle Design Protocol (MBDC, 2011) when producing the Mirra chair (Herman Miller, 2011) with the main considerations at this level of design being material health, material reutilization and renewable energy use. These factors in turn led to the specification of more chemically safe materials; the maximization of recycled material content in production; the potential to disassemble the chair at the end of its useful life in order to facilitate re-use of parts and the optimization of remaining parts that can be recycled. This resulted in a chair that is made from thirty-three per cent recycled material and that is ninety-six per cent recyclable at the end of its life. The Mirra chair also has improved longevity, facilitated by the specification of durable materials and the ability to easily remove and replace worn or broken parts. This improved performance is backed by a twelve-year warranty from Herman Miller. In addition to these direct design changes the energy used in production comes from wind turbines and landfill off-gassing. When comparing these strategies to those shown in Table I it is clear the Mirra chair exhibits improvements in the all the relevant areas discussed.

\section{New concepts}

Developing new concepts is a more radical approach than using strategies to redesign an existing product, service or system. It requires designers to think about underlying needs and how they can be fulfilled rather than focusing on methods of improving the current design. Considering innovative ways to achieve the same function or functions, such as replacing paper-based communication with email, can lead to more sustainable solutions.

The creation of new concepts requires designers to take a much more holistic view of what they are trying to achieve, with outcomes that may require multi-disciplinary collaboration to realize. Although by its nature a new concept cannot be easily planned for, 
there are some guiding principles (Van Hemel, 1998) than can be useful in this kind of fundamental rethinking of existing solutions.

- Dematerialization: This is not the same as reducing material usage in a redesign, but rather entirely replacing a physical object with an alternative means of providing the same service. An example of this could be substituting an answering machine with voice mail, or compact discs with downloadable digital audio files.

- Shared use of the product, packaging, service or visual communications: In this case the use of a product or service may be divided between a number of people. This can be observed where functions are combined, such as using packaging as part of the final product.

- Integration of functions: By combining several functions into one item, the environmental impact can be significantly reduced. The emergence of the smartphone has clearly demonstrated the importance of multifunctionality, combining facilities such as email, satellite navigation and music player along with the telephone in one device.

- Functional optimisation: New concept development starts with scrutiny of the function or functions that are trying to be provided. In the process of considering these functions it may become clear that some aspects of the design are unnecessary or could be supplied in a more sustainable way. This over use of materials can be seen in places such as the packaging of luxury goods or those marketed as gifts. However, in order to make any significant change in this area it may be necessary for a much wider organizational or cultural shift to take place before this type of packaging is seen as superfluous.

In order for this kind of approach to be successful, and for new concepts to be accepted, there may need to be a more meaningful change in the way users think about value 
and ownership. There is a complex and deep-seated desire amongst consumers to own the product or system they are using, and this requires changes to be made at a corporate and societal level in order to be undone. This change, along with the participation of a wide range of stakeholders, is necessary in order to innovate further and consider system innovation. However, despite the current situation limiting what can be achieved by designers alone and through their creativity and ingenuity, they can still influence more sustainable outcomes, and inspire others to do the same.

Knoend, lite2go: The lite2go (Knoend, 2007) is a light where the packaging is also used to create the lampshade. The main packaging is made from translucent polypropylene, with a paper label that contains the product information. Inside there is a low-energy light bulb, power cable with fittings, a further roll of plastic and an instruction booklet. To assemble the lamp, the light fitting screws on to the folded packaging, the light bulb is attached, and then the additional plastic creates a sleeve that fits over the top of the original packaging. This is a very simple product that only leaves a small amount of paper and hemp twine to be disposed of once made. This type of approach, where there is a shared use of materials for different stages in a products life, can improve resource use and enhance its sustainability.

Solar Desalination Still, Watercone: The Watercone (MAGE, 2011) is a small device invented by Stephan Augustine for transforming saltwater into drinking water just using sunshine. Most desalination is currently done on an industrial scale either using distillation or separating out the salt using a semipermeable membrane. These methods are energy intensive and require an infrastructure to distribute the purified water. The Watercone by contrast is an individual device that uses sunlight to distil the water. It is a clear plastic cone with an $80 \mathrm{~cm}$ diameter base that can either be floated directly on water, or placed on water that has been poured into the accompanying black pan. As the sun heats the water it evaporates, rises and 
then condenses on the inside of the cone, it then trickles down the inner wall of the cone into a rim at the base. Up to one and a half litres of water can be collected in twenty-four hours, and poured out through a spout at the top of the cone. Rather than redesigning current desalination systems the Watercone is a new concept that is portable, easy to use, and does not require any generated energy to use. Once distributed in areas of necessity, the Watercone not only has the potential to provide a reliable source of drinking water, but also gives greater control over the supply to those who really need it.

\section{System innovation}

To achieve higher levels of innovation this approach adopts a more strategic view and involves the participation of many different stakeholders including communities, government, companies and customers. Here designers are part of the development of new complete sustainable systems implying new lifestyles and ways to understand production and consumption of goods and services. This holistic approach not only responds to an evolution process but also aims to avoid the rebound effects often found as a result of partial improvements in products and services from less radical approaches (Roy, 2000).

Design for sustainability plays a very important role in this transformation of thinking, Manzini \& Vezzoli (2003) highlighted the role in terms of "the capacity to create new stakeholder configurations and develop an integrated system of products, services and communication that is coherent with the medium-long term perspective of sustainability being, at the same time, economically feasible and socially appreciable today”. Designers have a wide field to innovate, to be creative and to participate in the design and development of these new configurations that may require changes in infrastructure, technologies, values and behaviours (Bhamra \& Lofthouse, 2007). 
One concept that has gained attention as part of this radical approach is the development of product service systems (PSS). Organizations embarking on the journey at this point should rethink how they identify the needs of their customers, what they really are and then reimagining them in order to come up with innovative business offers based on combinations of products, services and systems. In general PSS can help to dematerialize offers by replacing products with services; can increase life-cycles and reduce the amount of waste by implementing reuse or sharing schemes; and can reduce materials flows and decrease energy consumption (Mont, 2002). These opportunities can have also positive implications in social and economic terms by creating new business opportunities, bringing producers closer to customers, creating collaborative networks between stakeholders and making basic services more accessible through communal infrastructure (Ness, 2007; Tukker \& Tischner, 2004).

The range of PSS that have been developed during the last twenty years come from a wide range of industries and applications, from rent and sharing business models specially in private transport to complex medical systems. They also include flooring systems; communal services of lighting and clothes washing; printing platforms; digital music distribution; food production and distribution systems as well as new furniture business models (Bhamra \& Lofthouse, 2007).

However, PSS are not the only route to achieve system innovation; in general a radical transformation of the business model including changing values, behaviour and infrastructure is part of this approach. Design for sustainability could contribute to this transformation by being part of the creative process of design and giving a sustainable perspective from the beginning of the process. Some of the possible actions and considerations that should be taken into account include:

- creating a lasting attachment between product, service or system and the user 
- $\quad$ using industrial ecology

- ensuring design ethics

- encouraging the fostering of resilient communities

- designing to increase the quality of life for all

Barclays Cycle Hire System: System innovation demands larger changes in how companies approach the design of products and services mainly to ensure consistency between products and services as part of the system. The main difference with the previous approaches is the idea of products and services creating value together around social, environmental and economic aspects as a system. One example that can illustrate this approach is the Barclays Cycle Hire System in London. The system is composed of docking stations, bikes, a payment platform, and an information system that together creates a transport system alternative in the city (Transport for London, 2011).

All the elements in this system have been designed to be part of the system and to create value together. For example, the bikes used in the system are modified designs that incorporate special features to perform as part of the system. They are tough in order to withstand public use by different kinds of customers in all extreme weather conditions. They have special locks and registration numbers to prevent thefts. They also have storage spaces, lights and bungee cord to serve the needs of commuters who carry bags or briefcases in their daily routine. In terms of the docking stations these are designed to safely store the bikes and allow the clients to make payments, collect and return the bikes. But they are also specially located around the city to provide the desired coverage as a transport system. Similarly, the information system provides a twenty-four-hour service with different commercial schemes as individual payments or as part of memberships (Transport for London, 2011). 
In this brief example it is possible to see the integration of products and services into a complex system that demands special design. If the objectives behind the system have a sustainable perspective, design has not only the responsibility to assure functionality and aesthetics but also the sustainable performance of the system. In this sense Barclays Cycle Hire System has important benefits in environmental terms as a substitute for cars, providing a zero emissions means of transport. Socially, it contributes to a less congested city, for tourists it is a useful opportunity to travel around the city and for daily users an alternative way to get to work quickly. In many cases the Barclays system is more comfortable way to travel, and can also claim health benefits for its users.

Despite the benefits there are also large changes in societal behaviour needed to make this kind of systems operable and profitable. In systems such as the Barclays Cycle Hire scheme there also needs to be educational campaigns and other incentives to attract users and achieve real long-term results.

\section{COMPARISON AND CRITICAL EVALUATION}

The approaches to sustainable design have been described as existing on a continuum from incremental change to radical innovation. Whilst innovations in function or systems can achieve greater improvements in eco-efficiency, they are more complex and require significantly more time to implement than the lesser changes needed to improve or redesign a product, service or system. Figure 4 represents this correlation between innovation and the increased levels of sustainability that can be achieved. The size of the squares represents the relative level of commitment required to achieve these levels of change, and the uncertainty that may be associated with this kind of transformation. 


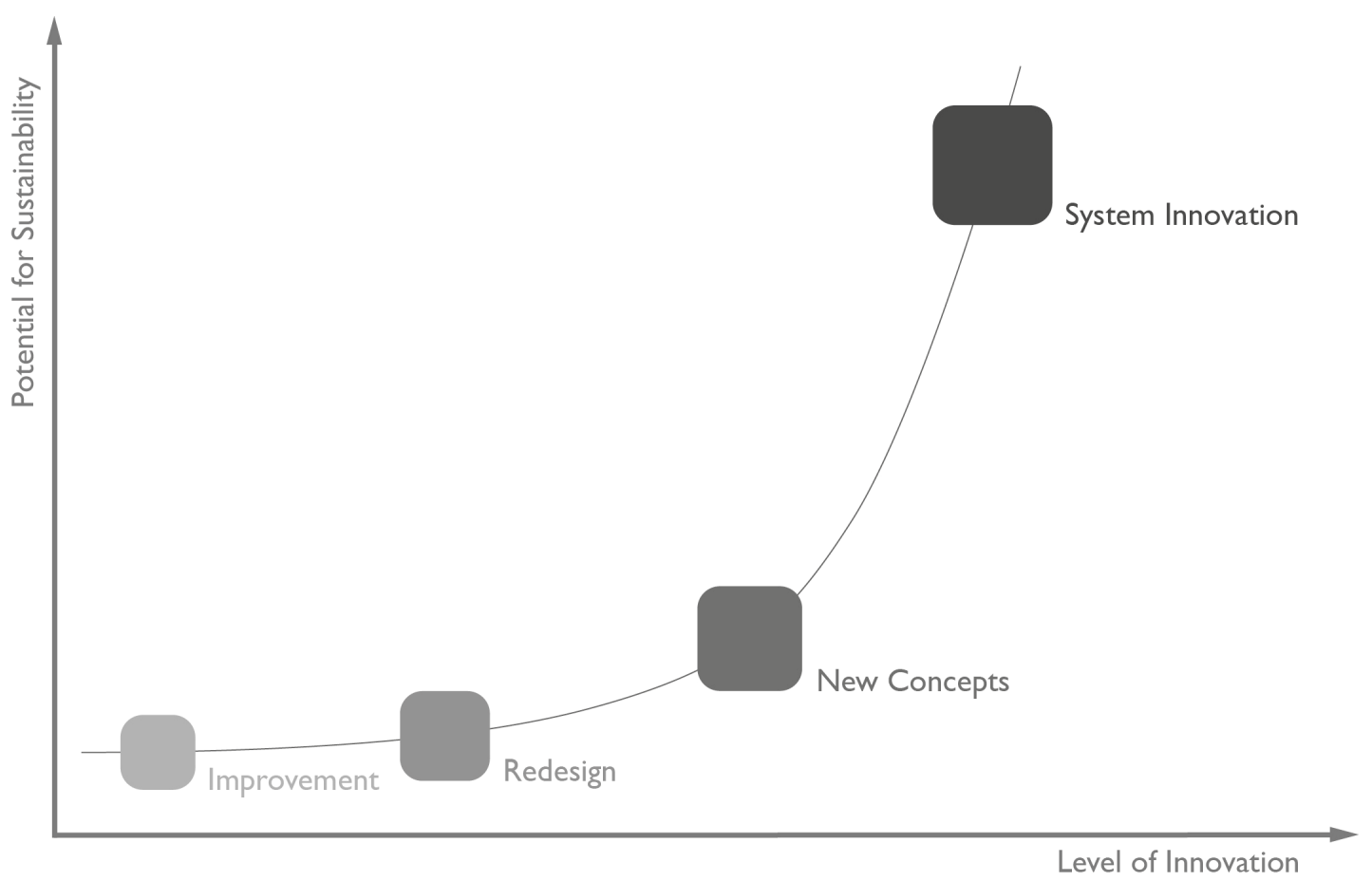

Figure 4: Influence that innovation can have on the sustainability of design

Legislation-led changes are likely to result in actions that ensure compliance rather than a wider change in thinking within an organization. Laws are generally made in reaction to events in the wider world, meaning they can be limited and slow to adapt to the realities of business. In addition regulations and directives are created at a macro level, often neglecting the significant variation that exists between the size of organizations leading to legislation and standards that can be too demanding for Small and Medium Enterprises (SMEs). In this context it is of particular concern because such a large proportion of design is carried out by SMEs. Redesign requires a more proactive approach, but can deliver clear benefits in terms of resource efficiency and associated cost savings without radically changing design outcomes and their related markets. A full life-cycle assessment does require time and expertise to produce useful results which can be a barrier to change, particularly for smaller organisations. However, there are a number of tools and strategies available to help designers focus their attention on the appropriate aspects of their work, leading to some improvement in sustainability. These incremental changes can only produce a maximum of an eighty per cent 
improvement in eco-efficiency, whilst with more radical innovations the reductions in environmental impact could be up to ninety-five per cent (Van Hemel, 1998). Unfortunately the ways of developing new concepts and creating system innovation are less well understood and much harder to make concrete. They both require the participation of a wide range of stakeholders, at the corporate level and in wider society, in order for changes to be successful. Embarking on this type of change carries a high level of risk, because there are no established methods for conducting a transformation of this sort, and the associated costs are generally high due to the need for significant changes in technology and infrastructure. However, if successful the potential rewards are far greater than with the more conservative changes, because innovation at this level can create entirely new business opportunities and significantly differentiate the product, service or system from those of competitors. There are ecological improvements derived from all of the changes discussed, but ultimately the greatest environmental benefits come from the most radical innovations and, despite the uncertainties, these in turn have the potential for providing the greatest financial reward.

\section{DISCUSSION}

The approaches for design for sustainability are proving to be useful and applicable to many industries. However, it is interesting to note that to date much of the focus has been purely on environmental issues rather than a more balanced approach that takes into account the social impact as well. The reasons for this are easy to understand as environmental issues are both easier to identify and measure, they are more tangible and easy to recognise. This lack of focus on social impacts has resulted in less radical and innovative solutions within design for sustainability something that needs to be addressed with some urgency if we are going to meet the challenging targets set for sustainable development in the future. 
Another limitation of current approaches is that they have been mainly oriented to producers and little is known about the consumers' side. Design for sustainability could have great impact in changing consumers' behaviour. The lessons learned by industry during the last fifty years should be used to develop more systemic approaches and their scope should be widened to include the whole of society.

\section{CONCLUSIONS}

Design for sustainability is now becoming better established within industry and the design community. As a result some interesting case studies are emerging. The current range of approaches outlined in this chapter provides a direction for designers and enable them to build skills, experience and confidence towards systems innovation. By enabling this transition to more innovation and sustainable solutions it is possible for industry to begin to benefit from the new approaches and realize the success that innovation and sustainability can bring.

\section{REFERENCES}

Bhamra, T., \& Lofthouse, V. (2007). Design for sustainability: A practical approach. (R. Cooper, Ed.). Gower Publishing Limited: Farnham, UK.

Brezet, H. (1997). Dynamics in ecodesign practice. Industry and Environment, 20, 21-24.

Brezet, H., \& Van Hemel, C. (1997). Ecodesign: A Promising Approach to Sustainable Production and Consumption (p. 346). UNEP 1E, Paris, ISBN 92-807-1631-X

DESA-UN. (1995). World Summit for Social Development Copenhagen 1995. Department of Economic and Social Affairs. Accessed 16 November 2011, from http://social.un.org/index/Home/WSSD1995.aspx 
Elkington, J. (1997). Cannibals with forks (p. 410). Capstone Publishing Limited: Oxford, UK.

European Parliament Council. (1994). European Parliament and Council Directive 94/62/EC of 20 December 1994 on packaging and packaging waste. Accessed 16 November 2011, from http://eur-lex.europa.eu/LexUriServ/LexUriServ.do?uri=CELEX:31994L0062:EN:NOT.

European Parliament Council. (2008). Directive 2008/98/EC of the European Parliament and of the Council of 19 November 2008 on waste and repealing certain Directives. Accessed 16 November 2011, from http://eurlex.europa.eu/LexUriServ/LexUriServ.do?uri=CELEX:32008L0098:EN:NOT.

European Parliament Council. (2009). Directive 2009/125/EC of the European Parliament and of the Council of 21 October 2009 establishing a framework for the setting of ecodesign requirements for energy-related products. Accessed 16 November 2011, from http://eurlex.europa.eu/LexUriServ/LexUriServ.do?uri=CELEX:32009L0125:EN:NOT.

Fiksel, J. R. (2009). Design for Environment: A guide to sustainable product development. McGraw-Hill: New York.

Gore, A. (1992). Earth in the Balance: Forging a new common purpose. Earthscan Publications Ltd: London.

Van Hemel, C. (1998). EcoDesign Empirically Explored: Design for Environment in Dutch Small and Medium Sized Enterprises. Delft University of Technology: The Netherlands.

Herman Miller. (2011). Design for the Environment. Herman Miller, Inc. Accessed 30 November 2011, from http://www.hermanmiller.com/About-Us/EnvironmentalAdvocacy/Design-for-the-Environment ISO (2006). ISO 14040:2006 Environmental Management - Life Cycle Assessment Principles and Framework. Geneva.

Knoend (2007). lite2go. Knoend. Accessed 5 July 2007, from http://www.knoend.com/productsF.htm

MAGE (2011). Watercone. MAGE Water Management. Accessed 30 November 2011, from http://www.watercones.com/ 
MBDC (2011). Cradle to Cradle Framework. McDonough Braungart Design Chemistry, LLC. Accessed 30 November 2011, from http://mbdc.com/detail.aspx?linkid=1\&sublink=6

Manzini, E., \& Vezzoli, C. (2003). A strategic approach to develop sustainable product service systems: examples taken from the "environmentally friendly innovation" Italian prize. Journal of Cleaner Production, 11, 851-857.

Mascle, C., \& Zhao, H. P. (2008). Integrating environmental consciousness in product/process development based on life cycle thinking. International Journal of Production Economics, 112, 5-17.

Mont, O. (2002). Clarifying the concept of product-service system. Journal of Cleaner Production, 10, 237-245.

Ness, D. (2007). Sustainable Product Service Systems: Potential to deliver business and social benefits with less resource use. Greening the Business and Making Environment a Business Opportunity. Bangkok, Thailand. 5-7 June.

Panasonic (2011). Intelligent Living Panasonic. Panasonic UK Ltd. Accessed 28 November 2011, from http://intelligent-living.panasonic.co.uk/washing-machines/our-technology.php Rainey, D. L. (2006). Sustainable Business Development: Inventing the Future Through Strategy, Innovation, and Leadership. Cambridge University Press: New York.

Redclift, M. (1994). Strategies for Sustainable Development: Local Agendas for the South. In M. Redclift \& C. Sage (Eds.), Strategies for Sustainable Development Local Agendas for the Southern Hemisphere (pp. 17-34). John Wiley \& Sons Ltd: New York.

Roy, R. (2000). Sustainable product-service systems. Futures, 32, 289-299.

Transport for London. (2011). Barclays Cycle Hire. Transport for London. Accessed 28 November 2011, from http://www.tfl.gov.uk/roadusers/cycling/14808.aspx

Tukker, A., \& Tischner, U. (2004). New business for old Europe: Product-Service Development as a means to enhance competitiveness and eco-efficiency. Greenleaf Publishers, Sheffield, UK 
United Nations (1992). Earth Summit 1992. United Nations Conference on Environment and Development (UNCED), Rio de Janeiro, 3-14 June 1992. Accessed 16 November 2011, from http://www.un.org/geninfo/bp/enviro.html

United Nations (1997). Kyoto Protocol. Framework convention on climate change. Accessed 16 November 2011, from http://unfccc.int/kyoto_protocol/items/2830.php

United Nations (2001). Johannesburg Summit 2002. World summit on sustainable development, 26 August - 4 September 2002. Accessed 16 November 2011 http://www.johannesburgsummit.org/html/brochure/brochure12.pdf United Nations (2010). Resolution A/RES/64/236. Accessed 16 November 2011http://www.uncsd2012.org/files/OD/ARES64236E.pdf WCED (1987). Our common future. Oxford University Press: Oxford, UK. WRI. (1992). World Resources 1992-93: A guide to the global environment. A Report by The World Resources Institute in collaboration with The United Nations Environment Programme and the United Nations Development Programme. Oxford University Press: New York and Oxford. 